writing, teaching skills, or even incorporating art into your work. This is not a suggestion to develop these skills at the expense of your research, particularly if you want to pursue an academic career, but it may be reassuring to have other options.

\section{Closing Thoughts}

The academic job market will likely look different in Fall 2020 , and these changes may persist for many years in the future as universities worldwide are facing budget shortages. I hope that these ideas give you a starting point if you are struggling right now, and I hope that you feel able to take the first steps in your job search.

Many early-career mathematicians are facing unique personal and professional struggles right now and I want to emphasize: you are not alone. Please know that in the midst of a global pandemic, it is okay to be struggling. It is okay to get less work done than you would otherwise. It is okay for your priorities to shift in new directions. Be gentle on yourself, and good luck on the job market!

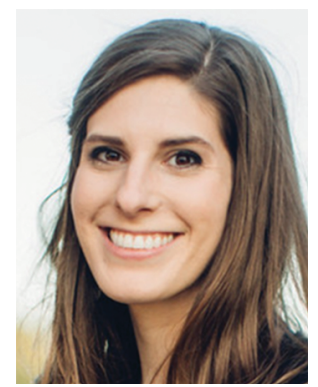

Kristin DeVleming

\section{Credits}

Author photo is courtesy of Mike Fiechtner.

\section{Looking Further Afield}

\section{Martin Guest}

As a potential academic job applicant, you already know that it is necessary to consider moving to some faraway place, possibly to a foreign country. This article is for people who are curious about working in Asia, which is about as far away from the US as possible-at least, if one adds to the actual distance the substantial cultural and linguistic separation.

Before giving some practical tips, I should make some general motivational remarks. Many mathematics students (myself included) just drift into having a mathematical career. This is nothing to be ashamed of: few undergraduate students can know what research is really like, but

Martin Guest is a professor of mathematics at Waseda University in Tokyo. His email address is martin@waseda.jp.

DOI: https://dx.doi.org/10.1090/noti 2158 developing and keeping an interest in the subject leads to a desire to know more, and is probably the only practical way to get started. Gradually one comes to realise that teaching and doing research in mathematics is a very worthwhile activity, and this gives one enough confidence to pursue it as a career. On the other hand, academic jobs are not easy to find, and combining teaching and research is a seven days a week commitment, with relatively low financial rewards by nonacademic standards. To be successful one needs more than interest and confidence. To be successful far away from the traditional support networks of family, friends, and academic mentors, needs still more. I feel that a crucial quality for any young academic, not just someone heading for a job in Asia, is first and foremost to have an absolutely uncompromising desire to understand some part of mathematics really well. This desire may be driven purely by feelings of competitiveness, or just from being unsatisfied with the way other people explain things and the desire to do it better, or any other number of reasons. If you acquire this quality, you will be able to enjoy mathematics and keep your balance, no matter where you are or what direction you follow.

If you already have a reason to work in Asia, such as a cultural or linguistic interest, this article is not for you, as you undoubtedly already have your own criteria. It is intended more for people who (as was my case, initially) may not think of Asia as a practical choice. My experience has been mainly in Japan, which is only one of the many countries in this part of the world, but some of what I have to say is likely to apply to any country where Chinese characters are (or were) used for communication. I have worked in Tokyo for more than 20 years, following about 15 years in the USA, and after spending the first 25 years of my life in the UK. I came to Japan for mathematical reasons, after making many visits and realising that I liked being here. I have been lucky to have supportive colleagues, and this brings me to my first piece of practical advice.

Personal contact is by far the best way to get started. Although it is true that English-speaking faculty members are increasingly sought after (for Japan, the internet JREC-IN Portal has some academic positions listed in English), some positions are advertised only as a formality (a candidate having been more-or-less selected in advance), and many jobs are advertised (in Japanese) only on posters pinned to bulletin boards. Without personal contacts, it can be difficult to find out what is available. Applying for jobs at random is most likely to yield nothing. On the other hand some academic positions are controlled by individuals with large research grants, and some positions are filled with almost reckless haste because of bureaucratic requirements, and this means you may have a much better chance of being selected than you imagined. Thus, it is very worthwhile to talk to visiting foreign researchers at seminars in your university, and keep in touch with them. In addition, it is not a waste of time to send a (very polite) letter or e-mail 
describing your work to a researcher at a foreign university. Needless to say, you must have at least some mathematical intersection with that person, and to discover this you must look at his/her published work.

It is best not to be too ambitious or demanding: if you insist on a tenure-track position right away, or salary matching, then you will not get very far. Respect for seniority is important, and the younger you are, the more respectful you are expected to be. If this does not appeal to you, then Asia is not for you. But respect works both ways-if you are polite and hard-working, then you will be treated well, and, yes, respected.

Fortunately mathematics is a very culturally-neutral subject, so you will have virtually no problems in daily mathematical life. You may find a position where everything (administrative work, not just teaching) can be carried out in English, but this is very much the exception. Even if your immediate colleagues can speak some English, support staff rarely do, and your life will be immeasurably smoother if you learn at least a little of the language (even for a one-year position this is worthwhile-and can be fun).

Regarding Japan specifically, academic life is different in a number of ways. Salaries are basically fixed on an age-related scale (within a given rank). This system has pros and cons, but it does remove a source of potential stress and conflict. Current salaries are not over-generous in my opinion, but are adequate, as inflation has been very low in Japan for many years. On the other hand research funds tend to be distributed quite democratically, and are designated primarily for travel and computer equipment, which can be advantageous to mathematicians. There is a very active domestic conference scene, and you will have many opportunities to give talks and make contacts. Safe and inexpensive business hotels, and excellent public transport by road, rail, and air, make travel in Japan very easy and convenient.

Teaching loads vary quite considerably. These are generously low at national (i.e., public) universities, but higher (sometimes much higher) at private universities. It is important to ask about this before accepting a position. Whether you will be able to teach in English at a Japanese university is very much a case-by-case matter. Of course, in a position which specifically solicits an English speaker, you will teach in English. But you may end up teaching very low-level courses to a small fraction of the university population, which will limit your activities. On the other hand, even in a position which is intended for Japanese speakers, you may be allowed to teach in English initially. In general, I would say there is little prospect of wholesale adoption of English as the language of instruction at Japanese universities, even at graduate school level.

Teaching (even in English) will probably not be exactly what you expect, even if the mathematics is the same. As a graduate from a US university, even with a brand new PhD, you will probably already have teaching experience, and this puts you in a strong position. In particular you will have your own ideas about what constitutes good teaching. On the other hand you should not expect colleagues to listen to your ideas, at least, initially. Just regard your teaching assignment here as an adventure, and keep your counsel for the right time and place, when it will be valued and appreciated.

What kind of people do well here? Prima donnas are frowned on. Exhibiting selfishness is a cardinal sin. People who cannot separate their work life from their personal life are regarded as eccentric; people who question every rule and regulation are not admired. Acting like an adult is important. Communal effort is important, in the sense of being willing to help with departmental tasks_-and this tends to create a positive atmosphere. You will be praised often, and never criticized, but this should not be taken at face value: you may have to work a little to find out what people really think. Some ability to "read the air" is needed. Needless to say, this way of life is not for everyone-you will have to make your own assessment! But, with an open mind (and, remember, your inner mathematical balance), working in Asia could be extremely rewarding. In Japan there are still very few non-Japanese faculty in mathematics departments, so you may even end up as a minor celebrity...

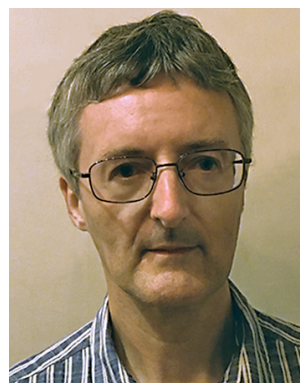

Martin Guest

\section{Credits}

Author photo is courtesy of the author.

\section{Applying for Jobs Outside the US}

\section{Daniel J. Thompson}

Are you an early career math job seeker? If so, have you considered applying for positions beyond the US job market? This article gives a starting point to understand some of the differences between job seeking in the US, and in

Daniel J. Thompson is a professor of mathematics at The Ohio State University. His email address is thompson@math.osu.edu.

DOI: https://dx.doi.org/10.1090/noti 2161 